\title{
CONTROL OF MECHANICAL PROPERTIES OF HIGH-STRENGTH STEELS THROUGH OPTIMIZED WELDING PROCESSES
}

\author{
M. FIEDLER, A. PLOZNER, B. RUTZINGER and W. SCHERLEITNER \\ Fronius International GmbH \\ 1 Froniusplaz, A-4600, Wels, Austria. E-mail: Scherleitner.Wolfgang@fronius.com
}

\begin{abstract}
Time of cooling in the range from 800 to $500{ }^{\circ} \mathrm{C}$ is a crucial factor, which determines the properties of welded joints of high-strength steels significantly. In field welding the cooling time $t_{8 / 5}$ can be steered by the heat input even at different wall thickness of the base materials used. Modern arc processes with reduced heat input allow, at the same deposition rates, increasing the stability of strength level due to optimized equipment settings. This paper compares the influence of conventional GMAW processes, like short-arc, pulsed-arc ones and new launched processes, on properties of the weld. From this point of view practical conclusions and recommendations can be derived to optimize weld properties. 5 Ref., 5 Figures, 5 Tables.
\end{abstract}

Keywords: arc welding, high-strength steels, heat input, weld properties

High-strength steels are used in many areas of the industry to reduce weight and material costs. Typical applications for this kind of steels are mobile cranes, offshore platforms, concrete pumps and pressure pipelines.

The advantage of TMC-processed fine-grain steels is to reach an optimum of strength and toughness. In general high-strength steels are used to reduce the wall thickness, which leads to lower weight and the already mentioned cost savings. Due to the low carbon content the weldability of these steels is good, for sure the manufacturers recommendation on steel and welding consumable should be followed.

The temperature-time gradient during welding and the material chemistry are crucial for the mechanical properties of high-strength steels. The temperature-time gradient is also described as $t_{8 / 5}$ time, and it is the duration of the cooling between 800 and $500{ }^{\circ} \mathrm{C}$. This time is significant responsible for the structure formation in the weld and HAZ.

Parameters, like material thickness, weld shape, bead or layer sequence, preheating temperature and heat input, influence the $t_{8 / 5}$ time. The heat input can be specific controlled by the selection of the welding process. This paper compares GMAW single-wire processes and tandem GMAW processes and their influence on mechanical properties. In particular conventional GMAW processes like short-arc process, modified processes like pulsed GMAW, GMAW PMC (with pulse multi control), LSC (with low spatter control), and tandem GMAW like cold metal transfer processes (CMT Twin and Time-Twin) are surveyed.
Compared welding processes. Short-arc GMAW. The short-arc process has continues wire feeding. Process regulation parameters are arc voltage and welding current. The cycle sequence can be described as follows. The wire is melted by the arc and a drop is formed. At the beginning of the short circuit the drop is contacting the surface of the workpiece. To break up the short circuit and to reignite the arc, a high current is needed. The surface tension of the weld pool and the high current create the so called pinch-effect, which detaches a drop at the wire end. At the peak value of the current the arc is reignited. High short circuit current may create extensive spatter [1].

Pulsed GMAW. This process is proven and known in the industry for many years, electronic-regulated power sources made it possible. The drop detachment is controlled by a material and shielding gas depending on current pulse. A short-circuit-free material transfer allows almost no spatter formation. The function principle is explained like following. A liquid weld pool and a molten welding wire end is caused by the base line current level (ground current phase). Due to each rise of current (current peak), also the current density rises, the Lorentz force will increase and the droplet is moving to the workpiece [2].

GMAW LSC. As already mentioned the short-arc process enables the material transfer with a high current peak, which leads to a possibly higher amount of spatter. High measure and control rates in the welding power source allow the LSC process to lower the current before the short circuit brake up. This stabilizes 


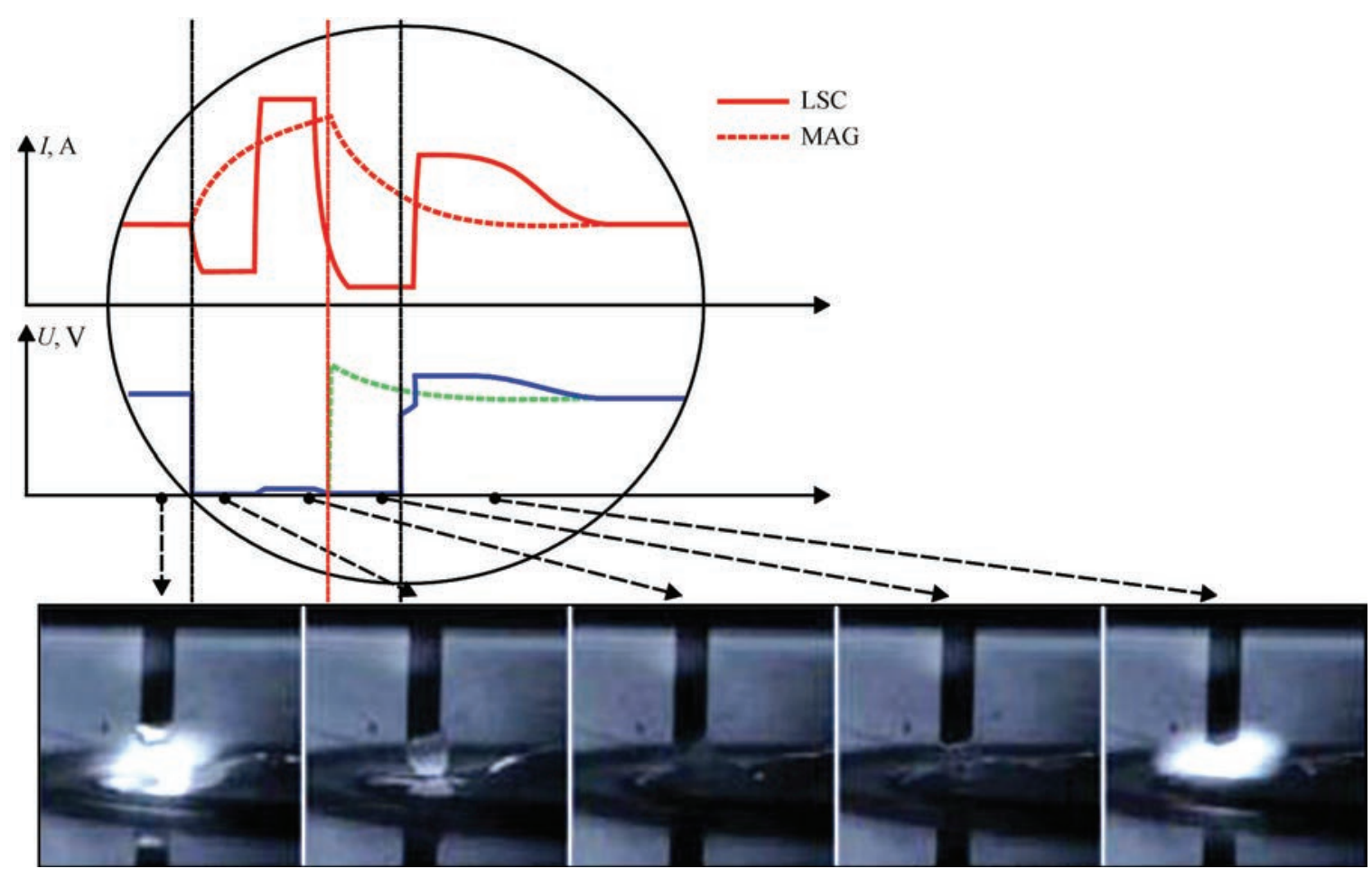

Figure 1. Current and voltage diagram for the LSC process

the welding performance and reduces the spatter to a minimum (Figure 1).

GMAW PMC. Pulse melt control is a further development of the pulsed GMAW process. New functions like penetration and arc length stabilizer, which have been realized by new algorithm, and higher calculation speed are integrated in the welding power source. TPS/i helps to control the arc in an efficient and easier way. Conventional welding machines use a constant wire feed rate. If the stickout of the welding wire is increased and the voltage is kept at the same level, the welding current will be decreased. This results in a reduction of the penetration, and a higher risk for lack of fusion may occurs. The «Penetration stabilizer» helps to detect variations in the stickout length and regulates according to the changes (with adjustment on the wire feed rate). The constant welding current helps to keep the penetration on a constant level over the whole length of the weld (Figure 2). Changes in the geometry of the bead or different welding speeds lead to variation in the arc length. The arc length stabilizer provides with a controlled short circuit during the drop detachment a constant arc length [3].

Tandem GMAW (Time-Twin). Tandem welding (Time-Twin) is performed using two separate welding electrodes, which are molten in one weld pool. Due to the separation of the electrical potentials, different arc combinations can be realized. This enables to regulate welding speed and deposition rate.

GMAW CMT Twin. CMT was basically developed as thin sheet metal joining process for the car indus- try. The main advantage of the CMT process is the low heat input due to the fact that the wire is pulled out of the liquid weld pool with an accordingly lower welding current. CMT Twin method is an upgrade of the tandem process. Similar to the tandem process, CMT Twin operates with two digital controlled power sources, which are completely independent from each other. The system makes a large spread of the wire feed rate possible and allows using two CMT arcs or the different arc combinations. The advantage of CMT Twin method is the arc stability and the reduced heat input.

Metallurgical aspects. New optimized welding processes are created by modified electrical parameters, especially the arc voltage and welding current have a main influence. This effect leads to variation in the heat input per unit length of weld (at constant welding speed) and therefore it influences the mechanical properties. The use of modern welding processes enables an easier handling of the weld pool and a higher arc stability, this results in higher welding speed. All these variation possibilities give a larger process window with regards to heat input and, for this reason, also for the cooling time $t_{8 / 5}$.

Using a modified arc process (at a comparable welding task) various mechanical properties can be expected. The LSC process, for example, reduces the welding current before the short circuit brake up, which leads to a lower heat input in comparison to conventional short-arc process. This effect gives lower heat input and leads to shorter cooling time. Ac- 


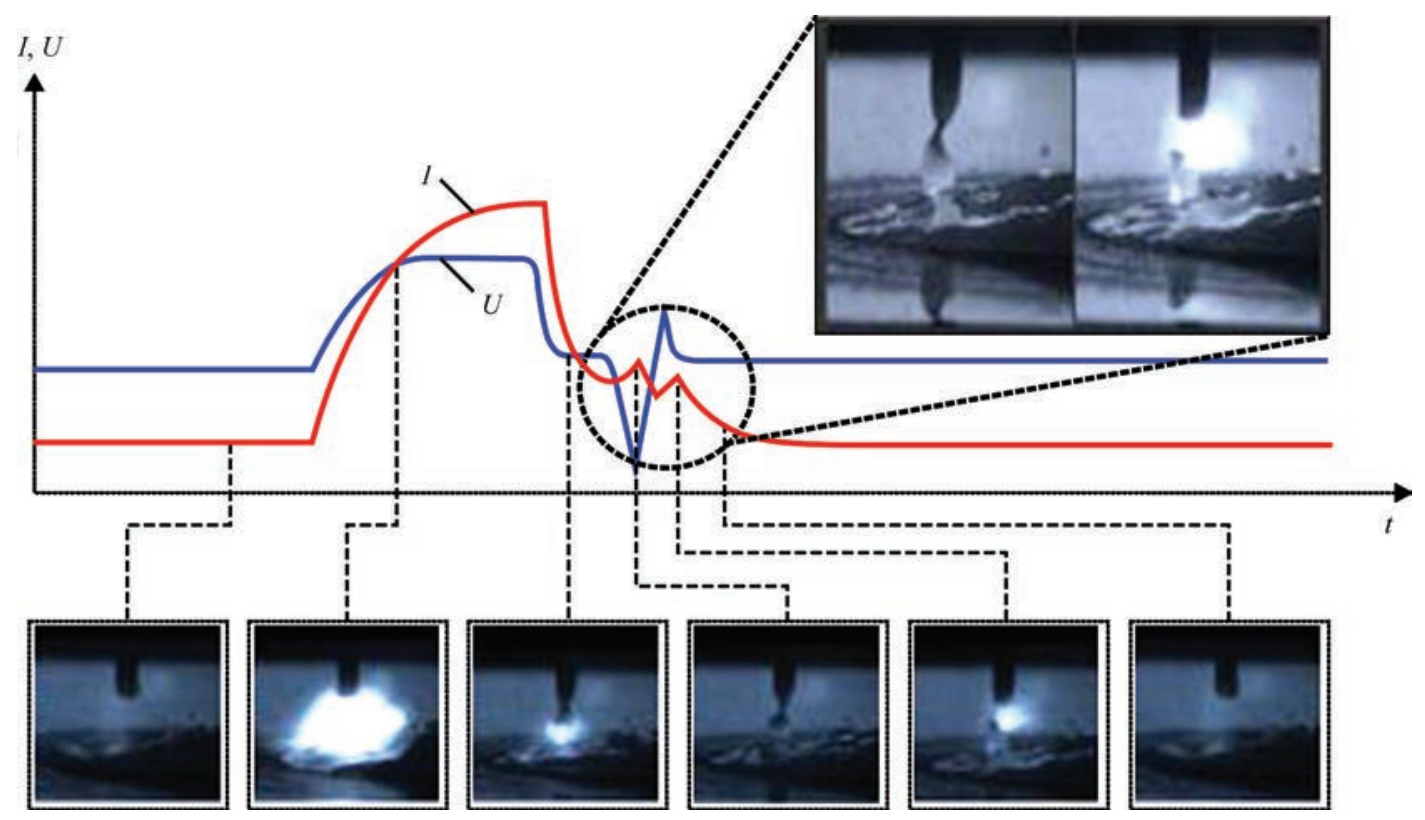

Figure 2. Current and voltage diagram for the PMC process

cordingly the strength is higher and the ductility is decreased due to a higher content of higher strength microstructure. Exists knowledge about these circumstances the welding engineer can take advantage out of that.

Experimental setup. To achieve comparable welding results, a standardized welding setup was chosen. Welding was performed with a robot in PA position in $\mathrm{M} 21$ shielding gas $\left(\mathrm{Ar}+18 \% \mathrm{CO}_{2}\right)$. Alform plate ${ }^{\circledR} 700$-M was used as the base material. Böhler Alform ${ }^{\circledR}$ 700-MC (metal-cored) and Böhler Alform $^{\circledR} 700$-IG (solid wire) with diameter of $1.2 \mathrm{~mm}$ were used as welding consumable. Weld and V-joints metal were surveyed, the interpass temperature for all tests was adjusted to $150^{\circ} \mathrm{C}$.

The test plates had dimension of $500 \times 150 \mathrm{~mm}$ and thickness of $20 \mathrm{~mm}$. Opening angle of $10^{\circ}$ was used with gap of $16 \mathrm{~mm}$ (all edges are buffered with similar material).

For the V-joints the dimensions were $700 \times 150 \times$ $\times 20 \mathrm{~mm}$; $60^{\circ}$ bevel angle was chosen, root gap was $2 \mathrm{~mm}$, and the ceramic backing was used. All test

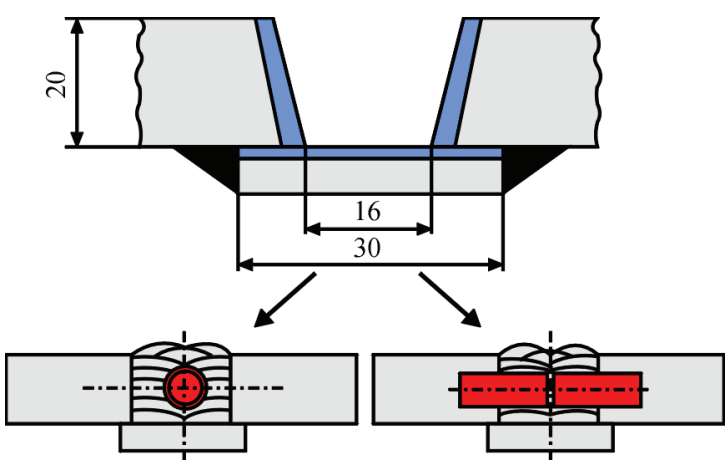

Figure 3. Edge preparation and sketches of weld metal specimens plates were welded in 6 layers, the V-joints — with 10 beads, the weld metal includes 12 beads.

Results. Weld metal. The setup and elaboration of the test samples was done according to standard EN ISO 18276 and EN ISO 16834 — in case of welding with adaption to robot method. Special emphasis was laid to use practical parameters also in regards to the repeatability of the joints. From weld metal longitudinal tensile specimen and impact specimen were taken. The impact specimens were tested from room temperature down to $-40^{\circ} \mathrm{C}$.

Figure 3 shows the bevel preparation and the sketches of weld metal specimens.

All specimens fulfilled the minimum requirement according to the standard. Due to chemical differences between solid and metal-cored wire, higher strength level is achieved with the usage of solid wires. The toughness values follow the common metallurgical correlation. This means that higher strength leads to lower toughness. Nevertheless tend the optimized single-wire GMAW processes for both products (solidand metal-cored wire) to result in higher toughness values in reference to the strength modification. Homogeneous welding parameter and homogenous solidification conditions (nucleation and precipitation) might have a beneficial influence on these circumstances.

Table 1 shows the results of the tensile test for weld metal. It also shows the connection between welding process and heat input. For practical reasons the technical term «heat input» was used without calculation of thermal efficiency. In this respect the documented parameters of the power source were used for calculation. Hence, a practical mode of operation was possible which is easy to follow by the user. 
Tabele 1. Yield strength, tensile strength and heat input for weld metal tested

\begin{tabular}{|c|c|c|c|c|}
\hline \multirow{2}{*}{ Process } & Welding wire & $\begin{array}{c}\sigma_{0.2}, \\
\text { MPa }\end{array}$ & $\begin{array}{c}\sigma_{\mathrm{t},} \\
\mathrm{MPa}\end{array}$ & $\begin{array}{c}\text { Q, } \\
\mathrm{kJ} / \mathrm{mm}\end{array}$ \\
\hline \multirow{2}{*}{ Standard } & Alform 700-IG & 763 & 814 & 1.44 \\
\cline { 2 - 5 } & Alform 700-MC & 736 & 787 & 1.27 \\
\hline \multirow{2}{*}{ PMC } & Alform 700-IG & 785 & 830 & 1.26 \\
\cline { 2 - 5 } & Alform 700-MC & 776 & 817 & 1.22 \\
\hline \multirow{2}{*}{ CMT-Twin } & Alform 700-IG & 877 & 926 & 1.11 \\
\cline { 2 - 5 } & Alform 700-MC & 786 & 828 & 1.05 \\
\hline \multirow{2}{*}{ Time-Twin } & Alform 700-IG & 814 & 857 & 1.26 \\
\cline { 2 - 5 } & Alform 700-MC & 778 & 814 & 1.19 \\
\hline \multirow{2}{*}{ Pulsed } & Alform 700-IG & 761 & 817 & 1.57 \\
\cline { 2 - 5 } & Alform 700-MC & 726 & 769 & 1.35 \\
\hline \multirow{2}{*}{ LSC } & Alform 700-IG & 767 & 814 & 1.51 \\
\cline { 2 - 5 } & Alform 700-MC & 727 & 772 & 1.37 \\
\hline
\end{tabular}

Due to controversial discussions about the investigation of the actual heat input, especially in regards to arc efficiency in tandem wire processes, it was relinquished as well.

The better wetting ability of the metal-cored wire allowed higher welding speeds which resulted in lower heat input. However, the batch caused lower strength values could not be compensated.

Due to its characteristic the CMT-Twin process provides low heat input which leads to higher strength levels.

Table 2 shows the results of impact test of weld metal. As already mentioned the higher strength (especially with the CMT-Twin process) gives lower toughness values. The optimized single-wire processes tend to have better toughness and strength performance.

Welded V-joints. The survey matrix for V-joints covers the investigation of strength values longitudinal and transverse to welding direction, the elaboration of longitudinal and transverse tensile samples and toughness analyses in the weld metal as well as a hardness profile over the entire weld.

Table 2. Impact force for weld metal tested

\begin{tabular}{|c|c|c|c|c|}
\hline \multirow{2}{*}{ Process } & \multirow{2}{*}{ Welding wire } & \multicolumn{3}{|c|}{ Impact force, J, at $T,{ }^{\circ} \mathrm{C}$} \\
\cline { 3 - 5 } & & 20 & 0 & -40 \\
\hline \multirow{2}{*}{ Standard } & Alform 700-IG & 118 & 113 & 64 \\
\cline { 2 - 5 } & Alform 700-MC & 137 & 126 & 97 \\
\hline \multirow{2}{*}{ PMC } & Alform 700-IG & 127 & 118 & 89 \\
\cline { 2 - 5 } & Alform 700-MC & 131 & 124 & 95 \\
\hline \multirow{2}{*}{ CMT-Twin } & Alform 700-IG & 82 & 77 & 69 \\
\cline { 2 - 5 } & Alform 700-MC & 103 & 96 & 79 \\
\hline \multirow{2}{*}{ Time-Twin } & Alform 700-IG & 130 & 123 & 98 \\
\cline { 2 - 5 } & Alform 700-MC & 108 & 104 & 86 \\
\hline \multirow{2}{*}{ Pulsed } & Alform 700-IG & 133 & 131 & 94 \\
\cline { 2 - 5 } & Alform 700-MC & 142 & 138 & 98 \\
\hline \multirow{2}{*}{ LSC } & Alform 700-IG & 128 & 116 & 77 \\
\cline { 2 - 5 } & Alform 700-MC & 152 & 141 & 108 \\
\hline
\end{tabular}

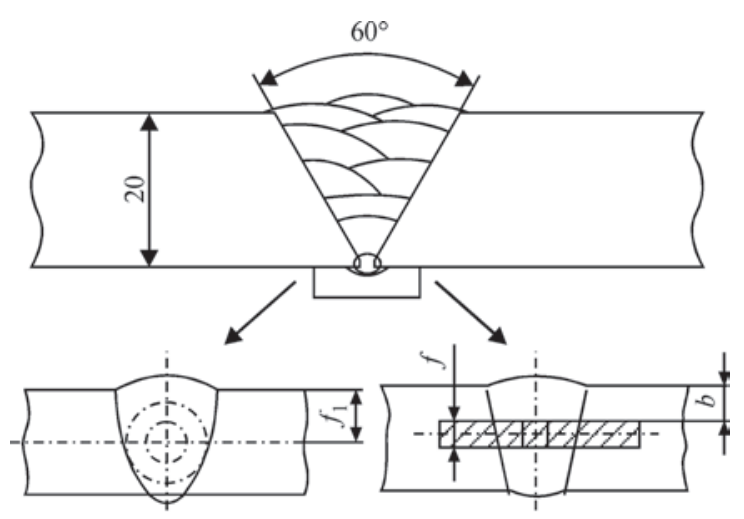

EN ISO 5178

EN ISO 9016

Figure 4. Layer sequence and sample preparation for welded V-joints test

Figure 4 shows the layer sequence and sample preparation.

The yield and tensile strength of the weld metal was investigated with longitudinal tensile samples according to the same procedure as described for the weld metal. For the welded joints similar parameters with practical adaption (on layer sequence) were used. Thereby no noteworthy discrepancy occurred.

Table 3 shows the results of tensile test for the V-joints. According to the already discussed difference in the layer sequence, the welding speed has been slightly increased, hence, the heat input was reduced. The dilution with the base material is the critical factor which influences the mechanical properties significantly [4]. Compared to weld metal test the heat input was lower, however the yield point was also reduced. The tensile strength followed the expected analogy according to the modified heat input. Therefore, a reduction of the yield point ratio $\left(\sigma_{0.2} / \sigma_{t}\right)$ in the weld can be realized.

By the use of a matched system between base material and welding consumable (Alform ${ }^{\circledR}$ welding system) optimized results can be achieved [5].

In particular, the toughness values in the joint (besides the dilution with the base material) were mainly

Table 3. Yield strength, tensile strength and heat input for welded V-joints tested

\begin{tabular}{|c|c|c|c|c|}
\hline Process & Welding wire & $\begin{array}{c}\sigma_{\mathrm{t}^{\prime}} \\
\mathrm{MPa}\end{array}$ & $\begin{array}{c}\sigma_{\mathrm{y}^{\prime}} \\
\mathrm{MPa}\end{array}$ & $\begin{array}{c}Q, \\
\mathrm{~kJ} / \mathrm{mm}\end{array}$ \\
\hline \multirow{2}{*}{ Standard } & Alform 700-IG & 714 & 872 & 1.32 \\
\cline { 2 - 5 } & Alform 700-MC & 712 & 806 & 1.25 \\
\hline \multirow{2}{*}{ PMC } & Alform 700-IG & 693 & 895 & 1.24 \\
\cline { 2 - 5 } & Alform 700-MC & 751 & 855 & 1.10 \\
\hline \multirow{2}{*}{ CMT-Twin } & Alform 700-IG & 833 & 888 & 0.97 \\
\cline { 2 - 5 } & Alform 700-MC & 824 & 902 & 0.79 \\
\hline \multirow{2}{*}{ Time-Twin } & Alform 700-IG & 798 & 873 & 1.13 \\
\cline { 2 - 5 } & Alform 700-MC & 757 & 837 & 1.14 \\
\hline \multirow{2}{*}{ Pulsed } & Alform 700-IG & 739 & 877 & 1.42 \\
\cline { 2 - 5 } & Alform 700-MC & 718 & 818 & 1.26 \\
\hline \multirow{2}{*}{ LSC } & Alform 700-IG & 715 & 854 & 1.38 \\
\cline { 2 - 5 } & Alform 700-MC & 701 & 810 & 1.27 \\
\hline
\end{tabular}




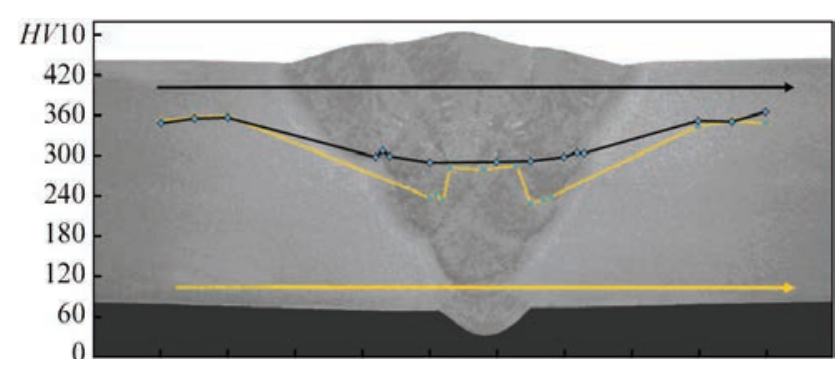

Figure 5. Hardness distribution over the weld weld-root-upper bead in PMC-welded joint with Böhler Alform ${ }^{\circledR} 700$-IG wire

influenced by the layer sequence. A comparison between weld and V-joints metal have been omitted due to the multidimensional parameter variations. Alike in the survey matrix (Table 4), an explicated correlation with the welding process is not possible. To get comparable results in this case a different testing setup with a similar layer sequence would be necessary. Essentially is that every process reached an impact force of $27 \mathrm{~J}$ at $-40{ }^{\circ} \mathrm{C}$.

Table 5 shows the evaluation of the transversal tensile strength as well of the fracture location. The fracture location depends on the lowest local stability in the weld or in the base material. In all cases the fracture strength is above $800 \mathrm{MPa}$.

Figure 5 shows the hardness profile over the weld. One hardness transverse was evaluated for the root, the other - for the upper layer. In any case, the hardness of the weld metal was always around $H V 10-280$ which is below the values of the base material.

\section{Summary and conclusions}

Modern arc processes do not only simplify the handling for the welder, they also enlarge the process window to control the mechanical properties for the welding engineer. The practical «modus operandi» (without additional measuring) was a particular focus in this paper. From a welder's point of view, higher welding speed with easier arc control could be achieved, which effects the heat input.

Especially the V-joints, which are in special focus for welding engineers, show in comparison to welds metal an improvement for the yield point ratio. This means that the lower yield point ratio value gives the higher reliability for the components.

Remarkable in this survey are the homogenous properties concerning strength and toughness by the use of modern arc processes. An improved toughness (at the same strength) can be recognized, this concludes of a homogenous solidification behaviour.
Table 4. Impact force values obtained

\begin{tabular}{|c|c|c|c|c|}
\hline \multirow{2}{*}{ Process } & \multirow{2}{*}{ Welding wire } & \multicolumn{3}{|c|}{ Impact force, J, at $T,{ }^{\circ} \mathrm{C}$} \\
\cline { 3 - 5 } & & 20 & 0 & -40 \\
\hline \multirow{2}{*}{ Standard } & Alform 700-IG & 170 & 156 & 101 \\
\cline { 2 - 5 } & Alform 700-MC & 134 & 123 & 79 \\
\hline \multirow{2}{*}{ PMC } & Alform 700-IG & 161 & 128 & 87 \\
\cline { 2 - 5 } & Alform 700-MC & 116 & 107 & 69 \\
\hline \multirow{2}{*}{ CMT-Twin } & Alform 700-IG & 128 & 113 & 90 \\
\cline { 2 - 5 } & Alform 700-MC & 98 & 95 & 72 \\
\hline \multirow{2}{*}{ Time-Twin } & Alform 700-IG & 127 & 113 & 74 \\
\cline { 2 - 5 } & Alform 700-MC & 113 & 104 & 78 \\
\hline \multirow{2}{*}{ Pulsed } & Alform 700-IG & 139 & 122 & 67 \\
\cline { 2 - 5 } & Alform 700-MC & 137 & 120 & 80 \\
\hline \multirow{2}{*}{ LSC } & Alform 700-IG & 160 & 141 & 83 \\
\cline { 2 - 5 } & Alform 700-MC & 146 & 137 & 82 \\
\hline
\end{tabular}

Table 5. Tensile strength and fracture location of transverse tensile samples of welded V-joints

\begin{tabular}{|c|c|c|c|}
\hline \multirow{2}{*}{ Process } & Welding wire & $\begin{array}{c}\sigma_{\mathrm{t}} \\
\text { MPa }\end{array}$ & $\begin{array}{c}\text { Fracture } \\
\text { location }\end{array}$ \\
\hline \multirow{2}{*}{ Standard } & Alform 700-IG & 832 & BM \\
\cline { 2 - 4 } & Alform 700-MC & 816 & WM \\
\hline \multirow{2}{*}{ PMC } & Alform 700-IG & 898 & WM \\
\cline { 2 - 4 } & Alform 700-MC & 870 & WM \\
\hline \multirow{2}{*}{ CMT-Twin } & Alform 700-IG & 858 & BM \\
\cline { 2 - 4 } & Alform 700-MC & 864 & BM \\
\hline \multirow{2}{*}{ Time-Twin } & Alform 700-IG & 870 & BM \\
\cline { 2 - 4 } & Alform 700-MC & 838 & BM \\
\hline \multirow{2}{*}{ Pulsed } & Alform 700-IG & 846 & WM \\
\cline { 2 - 4 } & Alform 700-MC & 818 & WM \\
\hline \multirow{2}{*}{ LSC } & Alform 700-IG & 818 & WM \\
\cline { 2 - 4 } & Alform 700-MC & 839 & WM \\
\hline
\end{tabular}

Hence modern arc processes do not only provide advantages for the welder (easier handling), they also influence in a positive way the formation of the weld metal microstructure.

The well tested and proven Alform ${ }^{\circledR}$ welding system can thus be used more flexible and with a high safety reliability. Modern welding power sources improve welding solutions.

1. Matthes, K.-J., Richter, E. (2008) Schweißtechnik Schweißen von metallischen Konstruktionswerkstoffen.

2. Artelsmair, J., Bruckner, J., Kazmaier, J. Der CMT-Prozess Ein neuer Prozess in der Fügetechnik.

3. Roßmann, F.-J. Neue Impulse für kontrolliertes und schnelles Schweißen.

4. Rutzinger, B. Influence of the welding process to the dilution rate, of weld overlays on unalloyed steel using the weld con-

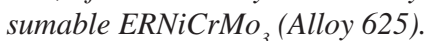

5. Fiedler, M., Rauch, R., Schnitzer, R. et al. Alform welding system - the world's first system for high-strength welded structures. In: Proc. of 68th IIW Ann. Assembly \& Int. Conf. (Helsinki). 